\title{
Powder and Solvent for Solution for Injection in Pre-filled Pen
}

National Cancer Institute

\section{Source}

National Cancer Institute. Powder and Solvent for Solution for Injection in Pre-filled Pen. NCl Thesaurus. Code C149798.

Medicinal product consisting of a powder and solvent for solution for injection presented in a pre-filled pen. The powder and solvent are contained in different compartments of the pre-filled pen, which contains all of the components necessary to prepare the solution for injection. 